\section{Commentary: The ultimate ex vivo lung perfusion: Xenogeneic cross-circulation}

\author{
Qimeng Gao, MD, ${ }^{\mathrm{a}}$ and Matthew G. Hartwig, $\mathrm{MD}^{\mathrm{b}}$
}

Although heavily popularized in the recent decade, the concept of ex vivo organ perfusion is not new. In their initial series of human liver transplants, Starzl and colleagues ${ }^{1}$ preserved liver allografts with ex vivo perfusion. The use of xenogeneic support too had its roots in the early days of transplantation - a team at Duke in 1994 successfully bridged a patient with fulminant liver failure to receiving a liver transplant using ex vivo pig liver perfusion support. ${ }^{2}$ Bacchetta's group married the 2 ideas of ex vivo organ preservation and xenogeneic support. In this issue of the Journal, O'Neill and colleagues ${ }^{3}$ provide a great overview of a novel technique-ex vivo lung preservation with xenogeneic cross-circulation.

In a porcine lung model, O'Neill and colleagues ${ }^{3}$ showed complete recovery of lung grafts subjected to prolonged cold ischemia following 24 hours of cross-circulation support without additional therapeutic interventions. ${ }^{4}$ The group went on to test the efficacy of allogeneic crosscirculation with a more profound injurious model using gastric aspiration, an injury that traditional ex vivo lung perfusion (EVLP) fails to reverse. ${ }^{5}$ After 36 hours of cross-circulation, lung grafts recovered and showed evidence of regeneration. ${ }^{6}$ Most recently, Hozain and colleagues $^{7}$ took this to the next level, attempting to recover discarded human lungs using a xenogeneic crosscirculation model. To prevent hyperacute rejection, porcine hosts received complement depletion and clinically used

\footnotetext{
From the ${ }^{\mathrm{a}}$ Department of Surgery, and ${ }^{\mathrm{b}}$ Division of Cardiovascular and Thoracic Surgery, Duke University Medical Center, Durham, NC.

Disclosures: Dr Hartwig consults for Bridge to Life, Paragonix, Medtronic, BioMedInnovations, and Intuitive Surgical. All other authors reported no conflicts of interest.

The Journal policy requires editors and reviewers to disclose conflicts of interest and to decline handling or reviewing manuscripts for which they may have a conflict of interest. The editors and reviewers of this article have no conflicts of interest.

Received for publication Aug 12, 2021; revisions received Aug 12, 2021; accepted for publication Aug 12, 2021; available ahead of print Aug 20, 2021.

Address for reprints: Matthew G. Hartwig, MD, Division of Cardiovascular and Thoracic Surgery, Duke University Medical Center, Box 3863, Durham, NC 27710 (E-mail: matthew.hartwig@duke.edu).

J Thorac Cardiovasc Surg 2022;163:1571-2

$0022-5223 / \$ 36.00$

Copyright (c) 2021 by The American Association for Thoracic Surgery

https://doi.org/10.1016/j.jtcvs.2021.08.042
}

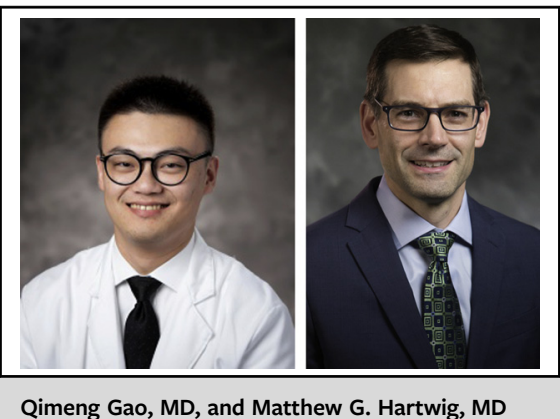

\begin{abstract}
CENTRAL MESSAGE
Xenogeneic cross-circulation is a promising method to recover marginal lungs. It may be more advantageous than EVLP but could introduce risks of zoonotic infections and sensitization to xenoantigens.
\end{abstract}

immunosuppression. During the 24-hour xenogeneic cross-circulation, PF ratio (the ratio of partial pressure of arterial oxygen to fraction of inspired oxygen), and compliance of the marginal allografts significantly improved. Importantly, one of the discarded human lungs that failed to recover on EVLP also had significant improvements.

Conventional EVLP offers 3 advantages over static cold storage. It prolongs preservation time, allows better graft evaluation, and offers a platform for therapeutic interventions. In comparison with current clinically available EVLP, xenogeneic cross-circulation may extend the preservation time further, thus allowing more time for therapeutic interventions to take effect. ${ }^{8}$ In addition, xenogeneic crosscirculation may recover marginal grafts better. In addition to circulatory function, a xenogeneic host provides an intricate systemic support across multiple systems. It may be challenging to elucidate the exact mechanisms behind the salutary effects of xenogeneic cross-circulation, but they likely include hormonal effects, cytokines, circulating xenogeneic cells, or even extracellular vesicles. One potential risk of xenogeneic cross-circulation is the exposure, albeit transient, to xeno-antigens. Hozain and colleagues ${ }^{7}$ found a degree of human-porcine chimerism, including porcine leukocytes, following cross-circulation. It is unclear whether those xenogeneic cells participate in the recovery of injured organs. Passenger leukocytes has long 
been recognized as a potential source of allosensitization. ${ }^{9}$ It is plausible that xenogeneic leukocytes acquired during cross-circulation could have a similar deleterious effect.

The use of xenogeneic support potentially could introduce ethical and safety concerns. This was well addressed by the authors. Approval from the Food and Drug Administration on the first intentional genomic alteration in GalSafe pigs last year ${ }^{10}$ certainly underscored the increasing acceptance of using genetically modified pig for therapeutic uses. In addition, the recent application of CRISPR (ie, clustered regularly interspaced short palindromic repeats) technology in creating porcine endogenous retrovirus-free pigs demonstrated a potential approach in creating a safe animal source for clinical use. ${ }^{11}$

\section{References}

1. Starzl TE, Groth CG, Brettschneider L, Penn I, Fulginiti VA, Moon JB, et al. Orthotopic homotransplantation of the human liver. Ann Surg. 1968;168:392-415.

2. Chari RS, Collins BH, Magee JC, DiMaio JM, Kirk AD, Harland RC, et al. Brief report: treatment of hepatic failure with ex vivo pig-liver perfusion followed by liver transplantation. N Engl J Med. 1994;331:234-7.
3. O'Neil J, Guenthart B, Hozain A, Bacchetta M. Xenogeneic support for the recovery of human donor organs. J Thorac Cardiovasc Surg. 2022;163:1563-70.

4. O'Neill JD, Guenthart BA, Kim J, Chicotka S, Queen D, Fung K, et al. Cross-circulation for extracorporeal support and recovery of the lung. Nat Biomed Eng. 2017; 1:1-15.

5. Khalife-Hocquemiller T, Sage E, Dorfmuller P, Mussot S, Le Houérou D, Eddahibi $\mathrm{S}$, et al. Exogenous surfactant attenuates lung injury from gastricacid aspiration during ex vivo reconditioning in pigs. Transplantation. 2014; 97:413-8.

6. Guenthart BA, O'Neill JD, Kim J, Queen D, Chicotka S, Fung K, et al. Regeneration of severely damaged lungs using an interventional cross-circulation platform. Nat Commun. 2019;10:1985.

7. Hozain AE, O'Neill JD, Pinezich MR, Tipograf Y, Donocoff R, Cunningham KM, et al. Xenogeneic cross-circulation for extracorporeal recovery of injured human lungs. Nat Med. 2020;26:1102-13.

8. Hozain AE, Tipograf Y, Pinezich MR, Cunningham KM, Donocoff R, Queen D, et al. Multiday maintenance of extracorporeal lungs using cross-circulation with conscious swine. J Thorac Cardiovasc Surg. 2020;159:1640-53.e1618.

9. Stone JP, Critchley WR, Major T, Rajan G, Risnes I, Scott H, et al. Altered immunogenicity of donor lungs via removal of passenger leukocytes using ex vivo lung perfusion. Am J Transplant. 2016;16:33-43.

10. Dolgin E. First GM pigs for allergies. Could xenotransplants be next? Nat Biotechnol. 2021:39:397-400.

11. Niu D, Wei HJ, Lin L, George H, Wang $\mathrm{T}$, Lee IH, et al. Inactivation of porcine endogenous retrovirus in pigs using CRISPR-Cas9. Science. 2017;357: 1303-7. 